\title{
A Clinical Study of Risk Factors and the Management of Surgical Site Infections in General Surgical Cases at Tertiary Care Center: A two-year Observational Study.
}

\author{
C. Arunkumar ${ }^{1 *}$, R. Chinnapan ${ }^{2}$
}

Received: 12 August 2021 / Accepted: 02 September 2021 / Published online: 20 January 2022

This article is published with open access at https://journal.astes.org.al

(C) The author(s) 2022. \& Copyright (C) 2022, the Albanian Society for Trauma and Emergency Surgery

(c) The Albanian Journal of Trauma and Emergency Surgery is an Open Access Journal. All articles are distributed under the terms of the Creative Commons Attribution Non-Commercial License: http://creativecommons.org/licenses/by-nc/4.0/) which permits unrestricted non-commercial use, distribution, and reproduction in any medium provided the original work is properly cited.

\begin{abstract}
Background: Surgical site infections penetrate to depths in tissues and cause simple superficial infections to sepsis. The aim of this study is to identify the incidence rate of surgical site infections and their risk factors at the surgical section of a tertiary care center.

Material and Methods: This retrospective observational study included 245 patients. The CDC class-wise breakup of would infection and the risk factors were recorded.

Results: The Incidence of surgical site infections was $11.4 \%$. $<20$ year aged patients showed $0 \%$ incidence, and $>60$-year aged patients showed $22.7 \%$ incidence. Malignancy observed as $31.3 \%$ incidence than without malignancy $(10 \%)$ risk factor $(\mathrm{p}=0.024)$. Among the origin, Lumbar sympathectomies and Breast surgery for malignancy showed the highest incidence (43.8\%), followed by Genitourinary tract surgeries with $22.9 \%$. Wound infection was more in an emergency $(15.4 \%)$ than elective procedures $(10.4 \%)$. The incidence rate increases from $7.9 \%(<1 \mathrm{hr})$ to $14.7 \%(1-2 \mathrm{hrs})$ regarding the duration of Surgery. The association of wound class with wound infection showed 13\% (clean), 3.3\% (clean-contaminated), 17.9\% (contaminated) the incidence of the study. The antibiotics usage shows a strong association with wound infection $(\mathrm{p}=0.015)$. The most common bacteria isolated were Staphylococcus and Streptococcus, Escherichia and Klebsiella species (60\% both), followed by Pseudomonas, Citrobacter, and others.

Conclusion: The factors which showed a strong association with wound infection were increasing age, surgical procedure, site of operation, presence of malignancy, urinary tract infection, lower respiratory tract infections, and exposure to antibiotics. Combination of clinical and microbiological means was the common mode of detection rather than individually.
\end{abstract}

Keywords: Wound infection, Diabetes Mellitus, surgical site infections, Staphylococcus.

\section{Introduction}

Surgical Site infections (SSI) are the infections following surgeries as hospital-acquired infections(HAI) [1,2]. The consequences imposed with SSI determine the need of strategies to prevent the infection. The estimated global prevalence of HAI approximately 1.4 million. Fan Y.et al.

Original article, no submission or publication in advance or in parallel

* Corresponding author:

C. Arunkumar, M.B.B.S., M.S

$\triangle \quad$ research.nmch@rediffmail.com

1 M.B.B.S., M.S., Civil Surgeon Specialist, Department of Surgery, Government District Head Quarters Hospital, Chittoor, A.P, India.

2 M.B.B.S., M.S., Professor \& Head, Department of Surgery, Apollo Institute of medical science and research, Chittoor, A.P. India. reported a $4.5 \%$ of SSI incidence in China from 2001 to 2012, and abdominal Surgery was the common surgical procedure [3].

According to patient's clinical condition, th risk factors to SSI referred as surgical infection risk index proposed by National nosocomial infection surveillance system (NNIS) [4], and American Society of Anesthesiologists index(ASA). Wound class represents the classification of the surgical Wound by the surgical experts in terms of the potential presence of microorganisms, and the duration of Surgery $[5,6]$. Other risk factors such as Body Mass Index (BMI), smoking, videoassisted procedures, blood transfusion, non-performance of preoperative baths, and pre-existing chronic diseases mentioned in reports and identified as associated with SSI studies on the subject $[7,8]$.

In India, the risk of acquiring SSI is high (4\%-30\%) [9]. Nonetheless, HAI prevention and control are not prioritized, and antibiotic resistance is the growing problem. 
Unfortunately, the surveillance data was still scanty. The bacterial burden level is a risk factor, but advanced surgery techniques and antibiotics have reduced the risk [10, 11].

The SSIs growth was depends on bacteria inoculum, the virulence of bacteria, microenvironment of the surgical site, and the host defense [12]. Haridas et al. reported 74\% of patients with SSIs (deep) were of gastrointestinal surgery and lower incidence in orthopedic surgeries [13].

Moreover, the publications related to SSI risk factors had negative impact on the it's management. Hence, there was need to explore the scope of patients developing an infection after surgery and identifying the risk factors at a tertiary care level.

The current study aimed to determine surgical site infection's incidence and their risk factors analysis at a tertiary care center.

\section{Patients and method}

Study design \& sample: This retrospective observational hospital-based study consists of 245 patients admitted at the surgical department at a tertiary care center between October 2017 and December 2019. The present target population comprises adult patients undergoing Surgery, either elective/ emergency, and developed the wound infection during their postop. Those who have another operation within one month postop were not included. Patients were clinically evaluated from admission upto discharge of 30 days postoperatively. Detailed history recorded, including demographics, comorbidities, antibiotic usage, blood transfusion, preoperative hospital stay, risk factors (diabetes, obesity), type/duration of Surgery. CDC criteria used to define the type of surgical Wound, i.e., Class I- Clean, Class II- Clean contaminated, Class III- Contaminated, Class IV- Dirty (Table 1).

Swabs were obtained from the postoperative wounds for microbiological Analysis. Antimicrobial susceptibility done by disc diffusion, and interpretation done according to the CLSI guidelines [14-16].

Statistical Analysis: Statistical analyses performed using the Statistical Package for the Social Sciences (SPSS), version 20 (SPSS, Inc. Chicago, IL, USA). Bivariate
Analyses carried out to know the association between risk factors with SSI were performed by $\chi 2$ and Fisher's exact tests. $P$-value $<0.05$ was considered statistically significant.

\section{Results}

The total no. of patients included was 245. The Incidence of Wound Infection in the present study is $11.4 \%$. The Median Age was 35 years (18 years and the Maximum Age was 75 years).

Surgeries: In the primary data collection, individual Surgeries were entered. While analyzing for Frequency of distribution and risk, they were subsequently grouped broadly under six categories.

Group I: Abdominal wall Surgeries: Inguinal

Herniorrhaphy/Hernioplasty [n=72(29.4\%)]

- Incisional Hernia Repair

- ANATOMICAL REPAIR

- MESH REPAIR

Group 2: Laporotomies: (Mainly G.I. Tract Surgeries) GJ Vagotomy [n=93(38\%)]

- Cholecystectomy Appendicectomy

- Resection and Anastamoses Perforation Closure Hemicolectomies etc.

Group 3: Genito Urinary Surgery Hydrocele - excision and eversion $[n=35(14.3 \%)]$

- Orchidopexies Orchidectomy

- Carcinoma Penis -Total Penectomy with perineal Urethrostony

- Partial Penectomy

Group 4: Head - Neck Surgery Thyroidectomies [n=22(9\%)]

- Salivary Gland Tumour - Surgeries

Group 5: Upper and Lower Limb Surgeries [n=7(2.9\%)]

- Amputations Above Knee

- Below Knee

- Varicose Veins -Trendelenberg Operation

- Avulsion \& Ligation Lintons Procedure

Group 6: Others [n=16 (6.5\%)]

- Lumbar - Sympathectomy

- Breast Surgery - Mastectomy with Axillary Clearance Laparotomies occupy a major part at a frequency

\begin{tabular}{|l|l|}
\hline Classification & Criteria: \\
\hline Clean: & $\begin{array}{l}\text { Elective, not emergency, non-traumatic, primarily closed; no acute inflammation; no break-in } \\
\text { technique; respiratory, gastrointestinal, biliary and genitourinary tracts not entered. }\end{array}$ \\
\hline Clean-contaminated: & $\begin{array}{l}\text { The urgent or emergency case is otherwise clean; the elective opening of respiratory, } \\
\text { gastrointestinal, biliary, or genitourinary tract with minimal spillage (e.g., appendectomy) not } \\
\text { encountering infected urine or bile; minor technique break. }\end{array}$ \\
\hline Contaminated: & $\begin{array}{l}\text { Non-purulent inflammation; gross spillage from the gastrointestinal tract; entry into biliary } \\
\text { or genitourinary tract in the presence of infected bile or urine; major break in technique; } \\
\text { penetrating trauma }<4 \text { hours old; chronic open wounds to be grafted or covered. }\end{array}$ \\
\hline Dirty: & $\begin{array}{l}\text { Purulent inflammation (e.g., abscess); preoperative perforation of respiratory, gastrointestinal, } \\
\text { biliary, or genitourinary tract; penetrating trauma }>4 \text { hours old. }\end{array}$ \\
\hline
\end{tabular}

Table 1: Classification of wounds based on the degree of microbial contamination [14] 


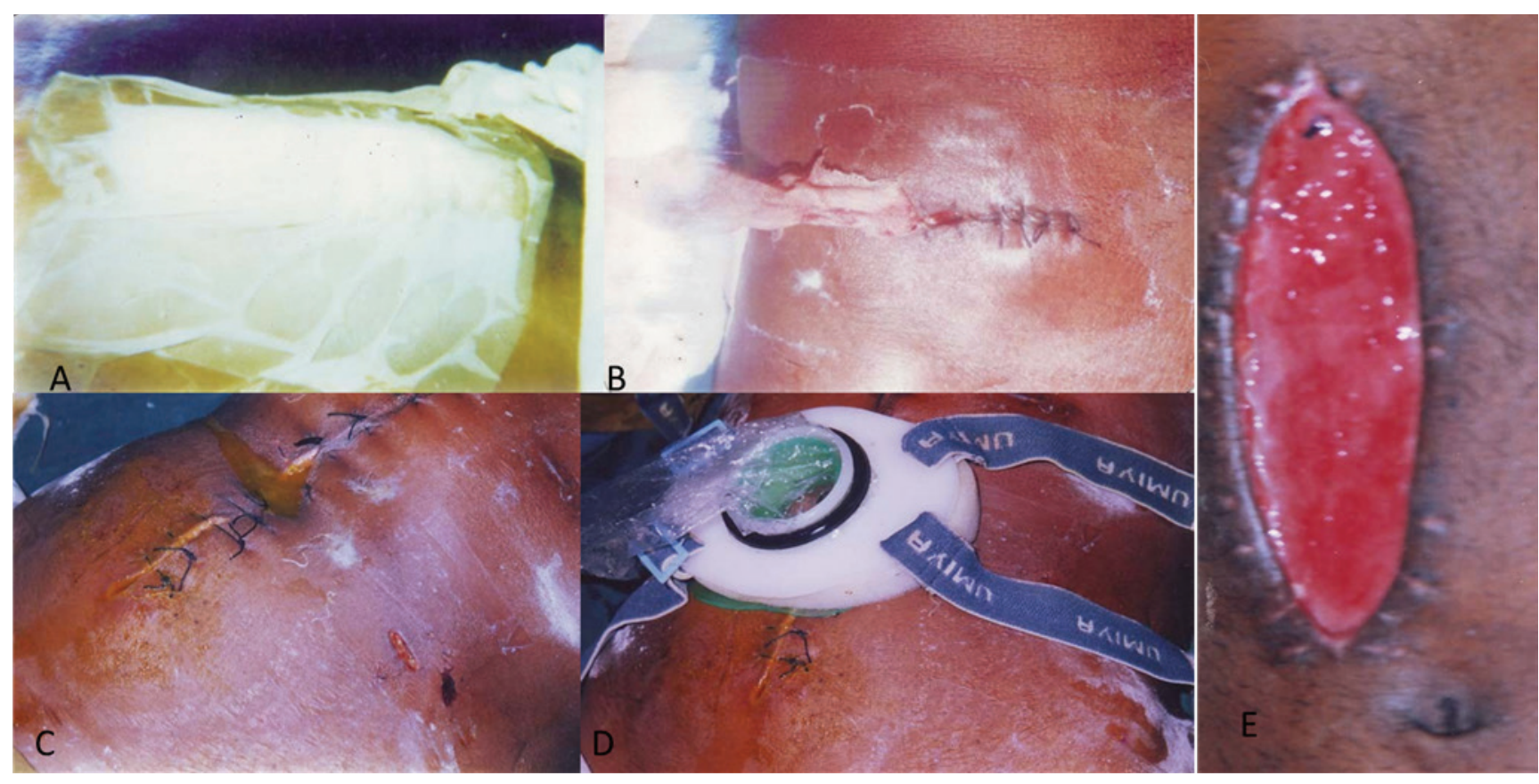

Figure 1. A. A case intra-abdominal Sepsis with Laprostomy. B. Infected Appendectomy Wound. C. Ente Rocutneous Fistula. D. Well Fitting Colostomy bag over Fistula. E. Wound gapping with Granulation tissue.

distribution of $38 \%$, followed by Abdominal wall surgeries (29.4), Genito Urinary Surgery (14.3\%), Head and Neck Surgery (9\%), others $(6.5 \%)$, and Limb Surgeries $(2.9 \%)$.

Distribution of Surgery based on wound class: There are 146 clean (59.6\%), Clean contaminated in 60(24.5\%), and contaminated in $39(15.9 \%)$, respectively.

Risk Factors: Anemia $32(13.1 \%)$ is the most prevalent risk factor, followed by Malignancy 16 (6.5\%), Diabetes Mellitus 12 (4.9\%), and tuberculosis 3(1.2\%), respectively. The other two factors, viz., Tuberculosis 3 (1.2\%) and Immunosuppression Illness $0 \%$, show a very low distribution frequency. Hence they were not considered for further statistical analysis.

Among the origin, Urinary tract Infection of 15 (6.1\%) and lower respiratory tract infection of $16(6.5 \%)$ were the most among the risk factors, followed by Focal Sepsis/ Remote Site Infection 10 (4.1\%). There were no cases of URI, and so it was not considered for further Statistical Analysis. 97 (39.6\%) among 245 were administered Preoperative Antibiotics for the indications (Figure 1 and Figure 2).

Duration of Surgery: Surgeries performed between 1 - 2 hours were more $109(44.5 \%)$ when compared to these done in less than 1 hour, $63(25.7 \%)$ and more than 2 hours $73(29.8 \%)$ (Table 2).

Method of detection: The highest number of wound infection cases were detected on the $4^{\text {th }}$ postoperative day. Most of them within the first week. Clinical and microbiological

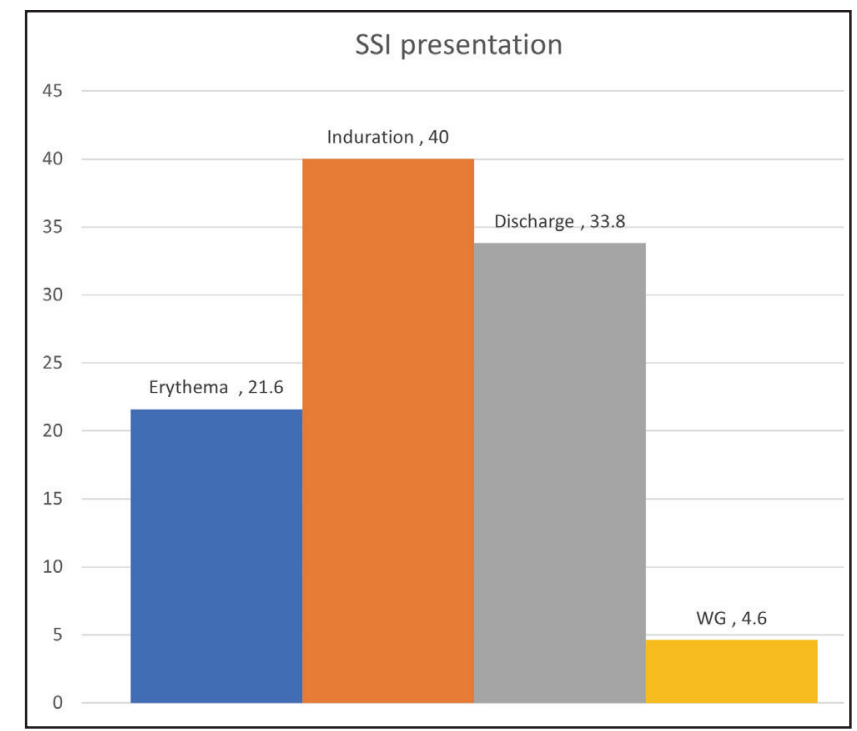

Figure 2. Surgical site infection presentation

methods confirmed it was $75 \%$ when compared to clinical impression only, i.e., $25 \%$. No case was detected purely on the growth of organisms, only without clinical features.

Organism cultured from the wound $(\mathbf{n = 2 1})$ : Table 3 shows Escherichia \& Klebsiella species observed a highfrequency distribution (33.3\%) closely followed by Staph \& Strep spp. (28.6\%). Among surgeons, Assistant Professors have performed a little more than half the number of Total Cases 125 (51\%); Trainees having performed 74 (30.2\%); Chiefs 40 (16.3\%)- Most of it would be patients, classified as ASA-III and above, contaminated cases, with underlying 
Table 2. Univariate Analysis:

Risk factors for wound infection

\begin{tabular}{|c|c|c|c|c|}
\hline S.No. & Risk Factor & $\begin{array}{l}\text { Sample } \\
\text { Size }\end{array}$ & $\begin{array}{l}\text { Incidence of Wound } \\
\text { infection(\%) }\end{array}$ & P-value \\
\hline \multirow[t]{3}{*}{1.} & Sex & & & \\
\hline & Male & 245 & 22/193 (11.4) & 0.977 \\
\hline & Female & & $6 / 52(11.5)$ & \\
\hline \multirow[t]{5}{*}{2.} & Age & & & \\
\hline & Up to 20 & & $0 / 37(0)$ & $0.010^{*}$ \\
\hline & $21-40$ & & $10 / 113(8.8)$ & \\
\hline & $41-60$ & 245 & $13 / 73(17.8)$ & \\
\hline & 60 and above & & $5 / 22(22.7)$ & \\
\hline \multirow[t]{7}{*}{3.} & \multicolumn{2}{|c|}{ Surgical Procedure } & & \\
\hline & \begin{tabular}{l|l}
1 &
\end{tabular} & & $6 / 72(8.3)$ & \\
\hline & 2 & & $7 / 93(7.5)$ & $0.000^{*}$ \\
\hline & 3 & 245 & $8 / 35(22.9)$ & \\
\hline & 4 & & $0 / 22(0)$ & \\
\hline & 5 & & $0 / 7(0)$ & \\
\hline & 6 & & $7 / 16(43.8)$ & \\
\hline \multirow[t]{5}{*}{4.} & \multicolumn{2}{|c|}{ Type of Surgery } & & \\
\hline & Clean & & 19/146 (13.0) & \\
\hline & \begin{tabular}{|l|} 
Clean- \\
\end{tabular} & 245 & & 0.052 \\
\hline & Contaminated & & $2 / 60(3.3)$ & \\
\hline & Contaminated & & $7 / 39(17.9)$ & \\
\hline \multirow[t]{3}{*}{5.} & Nature & & & \\
\hline & Emergency & & $8-52(15.4)$ & \\
\hline & Elective & 245 & $20 / 193(10.4)$ & 0.312 \\
\hline \multirow[t]{3}{*}{6.} & Anemia & & & \\
\hline & Present & & $5-32(15.6)$ & 0.424 \\
\hline & Absent & 245 & $23 / 213(10.8)$ & \\
\hline \multirow[t]{3}{*}{7.} & Diabetes & & & \\
\hline & Yes & & $2 / 12(16.7)$ & 0.633 \\
\hline & \begin{tabular}{|l|} 
No \\
\end{tabular} & 245 & $26 / 233(11.2)$ & \\
\hline \multirow[t]{3}{*}{8.} & Tuberculosis & & & \\
\hline & \begin{tabular}{|l|l} 
Yes \\
\end{tabular} & & $0 / 3(0)$ & 1.000 \\
\hline & No & 245 & $28 / 242(11.6)$ & \\
\hline \multirow[t]{3}{*}{9.} & Malignancy & & & \\
\hline & Yes & & $5 / 16(31.3)$ & $0.024 *$ \\
\hline & No & 245 & $23 / 229(10.0)$ & \\
\hline \multirow[t]{3}{*}{10.} & UTI & & & \\
\hline & Yes & 245 & $5 / 15(33.3)$ & \\
\hline & No & & $23 / 230(10.0)$ & $0.018^{*}$ \\
\hline \multirow[t]{3}{*}{11.} & LRI & & & \\
\hline & Yes & 245 & $6 / 16(50)$ & \\
\hline & \begin{tabular}{|l|l} 
No \\
\end{tabular} & & $22 / 229(9.6)$ & $0.004 *$ \\
\hline \multirow[t]{3}{*}{12.} & \multicolumn{2}{|l|}{ Focus of Infn. } & & \\
\hline & \begin{tabular}{|l|} 
Yes \\
\end{tabular} & 245 & $5 / 10(50)$ & \\
\hline & No & & $23 / 235(9.8)$ & $0.002 *$ \\
\hline \multirow[t]{3}{*}{13.} & \multicolumn{2}{|c|}{ Pre-Op. Antibiotics } & & \\
\hline & \begin{tabular}{|l|} 
Yes \\
\end{tabular} & 245 & $17 / 97(17.5)$ & $0.015 *$ \\
\hline & \begin{tabular}{|l|l} 
No \\
\end{tabular} & & $11 / 148(7.4)$ & \\
\hline \multirow[t]{4}{*}{14.} & \multicolumn{2}{|c|}{ Duration of Surgery } & & \\
\hline & \begin{tabular}{l|l}
$<1 \mathrm{Hr}$ \\
\end{tabular} & 245 & $5 / 63(7.9)$ & 0.342 \\
\hline & $1-2 \mathrm{Hrs}$ & & $16 / 109(14.7)$ & \\
\hline & $>2 \mathrm{Hrs}$ & & $7 / 73(9.6)$ & \\
\hline 15. & $\begin{array}{l}\text { Per-Op. } \\
\text { Antibiotics }\end{array}$ & 245 & & $0.015 *$ \\
\hline & Yes & & $17 / 97(17.5)$ & \\
\hline & No & & $11 / 148(7.4)$ & \\
\hline
\end{tabular}

\section{* - Statistically Significant}

Malignancy, etc. The most frequent surgical site infection is induration. The drug ciprofloxacin has more sensitivity than other drugs. (Figure 3)

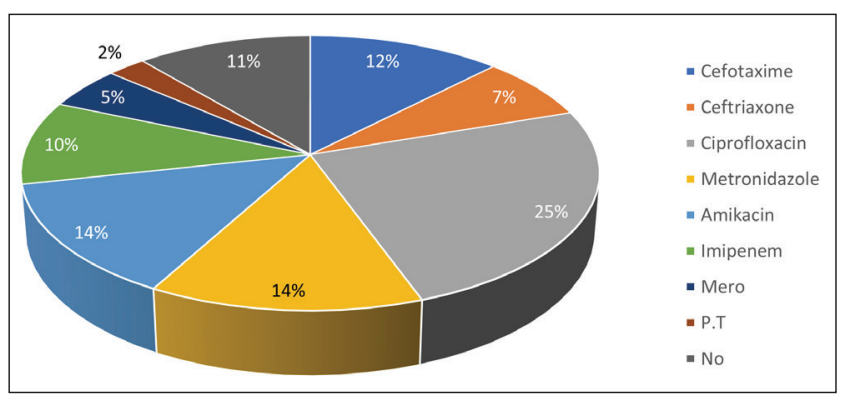

Figure 3. Antibiotics distribution

The outcome of wound infection [ $\mathrm{n}=28]$

Out of 28 Infected cases. Twenty-six cases were resolved without major complications. Whereas 2 cases went on to have other complications.

\begin{tabular}{|l|c|c|c|}
\hline Organism & & Frequency & Percent \\
\hline No Growth & & 1 & 4.8 \\
\hline Staph Strep species & & 6 & 28.6 \\
\hline Klebsiella & $\&$ & & \\
\hline Escherichia & & 7 & 33.3 \\
\hline Pseudomonas & & 3 & 14.3 \\
\hline Citrobacter Spp. & & 2 & 9.5 \\
\hline Others & & 2 & 9.5 \\
\hline Total & & 21 & 100 \\
\hline
\end{tabular}

Table 3. Distribution of organisms Isolated

\section{Discussion}

In this study, the incidence SSI observed as $11.4 \%$. This was comparable to other studies, where the infection rate was ranged from $20 \%$ to $76.9 \%$ [18-22].

The rate of infection was highest in contaminated type of wounds; Incidence among clean-contaminated (3.3\%) and contaminated (17.9\%) categories compares favourably with other studies, whereas Incidence among clean cases (13.0\%) is markedly high, which in turn might be responsible for the overall incidence $(11.0 \%)$. Similar rates were observed in other studies $[17,18]$.

Age appears to be associated risk factor for wound infection $[23,24]$. In our study, there was gradual increase from $0 \%$ in the under 20 age group to $22.7 \%$ in persons aged 60 and above with a p-value of 0.01 .

Surgical Procedures were categorized based on the operation site into six groups as Abdominal wall surgeries: Laparotomies, Genitourinary surgical, Head and Neck Surgery, Limb surgeries, and other areas in that order. The results show that they were associated Risk factors for wound infection $(\mathrm{p}=0.000)$. Among the sites as such, "others" comprising of Lumbar Sympathectomy and Mastectomy 
with Axillary clearance major surgeries shows the high incidence of wound infection. The influencing factor may be the underlying Malignancy \& Focal sepsis (gangrene toe, non-healing ulcer foot, etc.) may be the reason for this association. Genitourinary Surgeries fall next in line with an incidence of $22.9 \%$. The preponderance of urinary tract infection may be the predisposing factor.

Laparotomies comprising mainly of surgeries on the G.I. tract showed an incidence of $7.5 \%$, which is acceptable considering that the group includes contaminated cases, emergency procedures, lengthy operation, and underlying malignancy were potential Risk factors. However, anaemia, and diabetes mellitus were high in the elective (38\%) than emergency (33\%) surgery. In Aurangabad, the SSI rate in emergency surgeries were not higher than in elective surgeries [17]. Prolonged operations may increase the chance of Wound infection.

In Abdominal wall surgeries, the Incidence was 8.3\%, which is high for this category as most cases are "clean" cases and performed as Elective procedures. Head and Neck surgeries involved mostly clean cases, whereas Limb surgeries include mostly lower limb amputation-Above/ below the knee- for "Diabetic Foot." The removal of the nidus of Infection and adequate coverage with antibiotics may be the reason for the absence of post-operative Wound Infection. This study denotes the wound class (based on contamination), which is considered an important risk factor and a predictive factor of wound infection.

Among the factors mentioned above, "malignancy" is one factor which has a strong association as a Risk factor with an incidence of $(31.3 \%)$ and a $p=0.024$ in our present study.

All these three factors, whose Incidence among patients in the wound infection are as follows - UTI (33.3\%), LRI $(37.5 \%)$, Focus of Infection $(50 \%)$ and with $p$ values $0.018,0.004,0.002$ respectively show a strong association as a risk factor for wound infection. Even though these factors are identified preoperatively and treated, they have demonstrated a strong association as a risk factor for wound infection. The reasons for this may be inadequate control of Infection, the resistance of bacteria to the antibiotics exposed. Preoperative antibiotics are known to decrease the Incidence of SSI cases. The risk of wound infection is proportional to the length of operative procedure [2527]. The present study shows a higher incidence of wound infection among surgeries performed between 1-2 hr $(14.7 \%)$ and an incidence of $7.9 \%$ in the $<1 \mathrm{hr}$ category and $9.6 \%$ when it exceeded $2 \mathrm{hrs}$. It would be relevant to recall that in this study, the duration was fixed arbitrarily and was not done on the lines recommended in the recent literature, which states that a procedure is deemed "lengthy" only if it crosses the $75^{\text {th }}$ percentile in terms of time consumed. Studies also reported a similar observation [18-21].

The present study shows a high incidence of wound infections among patients operated upon by chiefs, $17.5 \%$, $11.2 \%, 8.1 \%$, and $16.7 \%$ among surgeries performed by assistant professors, trainees/PGs, and interns. Though this observation is not statistically significant $(p=0.487)$, the higher Incidence among surgeries performed by chiefs can be explained by the fact that they tend to operate on grossly contaminated cases, patients with pre-existing illness (e.g., ASA III and above, Malignancy, etc) and also perform lengthy surgeries. All these factors are potential risk factors, contribute to the current observation, and exclude any stigma attributable to the performing surgeon. On the other hand, trainees show the least Incidence of wound infection, which may be because they operate mostly uncomplicated cases.

Exposure to antibiotics in the preoperative period showed a strong association with wound infection $(p=0.015)$. The reasons may be inadequate infection control for which the antibiotics were started or bacterial resistance to the exposed antibiotics. Very low sensitivity was observed with cephalosporins \& fluoroquinolones (10\% and 58\%). This may occur due to drug overuse and the prevalence of extended-spectrum beta-lactamases (ESBLs). On the other hand, Pseudomonas isolates were showed high sensitivity to piperacillin-tazobactam, ceftazidime, and imipenem at $83.5 \%, 83 \%$, and $100 \%$ respectively. In the sample studied, 28 out of 245 patients had wound infection.

Most of the cases detected in the first week after surgery. Nearly $50 \%$ of them were detected on the 4 th $(28.6 \%)$ and 5 th $(21.4 \%)$ postoperative days. The most delayed detection was on the 8th postoperative day. This differs from other studies where the maximum number was detected during the $2^{\text {nd }}$ week. With the concept of day-care surgery, identification of wound infection gets even more delayed as it is picked up only during the surveillance follow-up period. The present study was done in clinical, and microbiological. The clinical method alone was employed to detect $2.5 \%$ of cases and the rest by both clinical and microbiological means. Though everyone was aware of the criteria to diagnose a wound infection, it was not done by a single person. It was done by different people at different times. As discussed already, there might be an element of observer bias in this modality of detection. In the present study, 21 out of 28 infected patients had a swab sent for culture and sensitivity at the time of detection. The results reveal the following distribution pattern. Klebsiella, Escherichia species (33.3\%), and Staphylococcus \& Streptococcus species (28.6\%) occupy more than $60 \%$ of the total, Pseudomonas (14.3\%) and Citrobacter (9.5\%) and others (9.5\%) form the rest of the group. No growth was reported from one of the isolates $(4.5 \%)$. This is in line with other studies. Mumbai study has also reported $17.6 \%$ culture-negative SSI cases. In the present study, 26 out of 28 wound infections resolved. One patient went into septicaemia of the remaining two, and the other had cutaneous gangrene and septicaemia.

The closed wounds and their healing depend on expertise and technique [2]. In our study, the incidence of infections in relation to various types of closure methods depicted in Figure 4. 


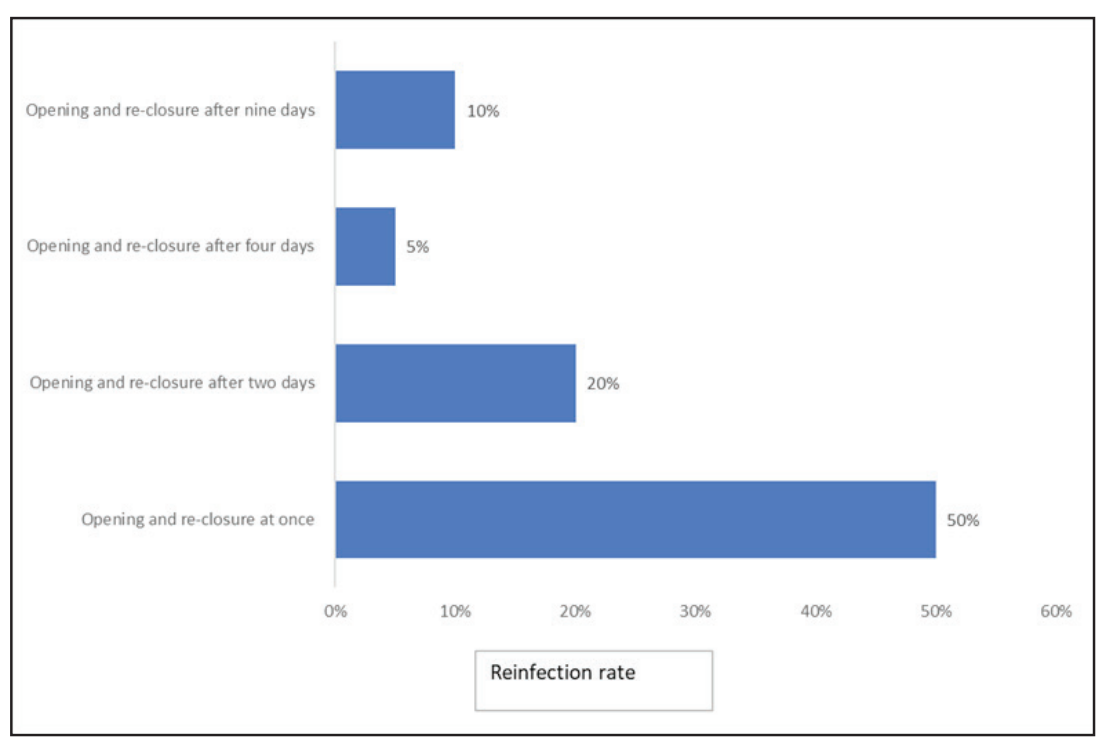

Figure 4. Reinfection rate

Types of bacteria colonize the skin up to $50 \%$ with Staphylococcus aureus. Preoperative wash with chlorhexidine may decrease the bacterial count on the skin, which results in decrease wound contamination [28-30]. In our study, shaving time was $>2 \mathrm{hr}$ before Surgery, the clean wound infection rate was $2.3 \%$. If body hair has been clipped, the infection rate was $1.7 \%$. Hence, shaving should be done at close time of the Surgery $[26,31]$.

\section{Conclusion}

Efforts to needed to decrease the Surgery duration without effecting the safety or efficacy. Thorough investigations of the patient and their risk factors should be assessed, and appropriate management should be followed to enable the patient to withstand stress during Surgery. In addition, utmost post-operative care and immunity-boosting should help to decrease the further occurrence of infections.

\section{Declaration of Conflicting Interests and Ethics;}

The authors declare no conflict of interest. T his research study complies with research publishing ethics. The scientific and legal responsibility for manuscripts published in Albanian Journal of Trauma and Emergency Surgery AJTES, belongs to the author(s).

\section{Acknowledgements: None.}

\section{Conflict of interest}

There were no conflicts of interest to declare by the authors.

\section{References}

1. Centers For Disease Control and Prevention. ProcedureAssociated Module: surgical site infection event [Internet] Atlanta: 2016. 29.

2. Anderson DJ, Podgorny K, Berríos-Torres SI, Bratzler DW, Dellinger EP, Greene L, Nyquist AC, Saiman L, Yokoe DS, Maragakis LL, Kaye KS. Strategies to prevent surgical site infections in acute care hospitals: 2014 update. Infect Control Hosp Epidemiol. 2014; 35:S66-88.

3. Fan Y, Wei Z, Wang W, Tan L, Jiang H, Tian L, et al. The Incidence and distribution of surgical site infection in mainland China: a meta-analysis of 84 prospective observational studies. Sci Rep. 2014;4:1-8.

4. Centers For Disease Control And Prevention (CDC) The National Healthcare Safety Network (NHSN) Manual: patient safety component protocol. Atlanta: 2008. 98.

5. Ercole FF, Chianca TC, Duarte D, Starling CE, Carneiro $M$. Surgical site infection in patients submitted to orthopedic Surgery: the NNIS risk index and risk prediction. Rev Lat Am Enfermagem. 2011 Mar-Apr; 19(2):269-76.

6. Korol E, Johnston K, Waser N, Sifakis F, Jafri HS, Lo M, Kyaw $M H$. A systematic review of risk factors associated with surgical site infections among surgical patients. PLoS One. 2013; 8(12):e83743.

7. Lotfi CJ, Cavalcanti Rde C, Costa e Silva AM, Latorre Mdo $R$, Ribeiro Kde C, Carvalho AL, Kowalski LP. Risk factors for surgical-site infections in head and neck cancer surgery. Otolaryngol Head Neck Surg. 2008 Jan; 138(1):74-80.

8. Franco LMC, Ercole FF, Mattia A. Infecção cirúrgica em pacientes submetidos a cirurgia ortopédica com implante. Rev SOBECC. 2015;20(3):163-170 
9. Suchitra J, Lakshmidevi N. Surgical site infections: assessing risk factors, outcomes and antimicrobial sensitivity patterns. Afr J Microbiol Res 2009;3:175-9.

10. World Health Organization. Report on the burden of endemic health careassociated Infection worldwide: clean care is safer care. Geneva [Switzerland]: WHO Document Production Services; 2011.

11. Subbalaxmi M, Lakshmi V, Lavanya V. Antibiotic resistance: experience in a tertiary care hospital in south India. J Assoc Physicians India 2010;58(Suppl): 18-22.

12. Singh R, Singla P, Chaudhary U. Surgical Site Infection: Classification, Risk factors, Pathogenesis and Preventive Management. International Journal of Pharma Research and Health Sciences. 2014; 2(3): 203-214.

13. Haridas M, Malangoni MA. Predictive factors for surgical site infection in general Surgery. Surgery. 2008; 144(4): 496-501. doi: 10.1016/j. surg.2008.06.001.

14. Berard F, Gandon J. Postoperative wound infections: the influence of ultraviolet irradiation of the operating room and of various other factors. Ann Surg 1964; 160(Suppl 1): 1-192.

15. Koneman EW, Allen SD, Janda WM, Schreckenberger PC, Winn WC Jr, editors. Color Atlas and Textbook of Diagnostic Microbiology. 5th Ed. Lipincott-Raven Publishers; Philadelhia: Pa: 1997.

16. Bauer AW, Kirby WM, Sherris JC, Turck M. Antibiotic susceptibility testing by a standard single disc method. Am J Clin Pathol. 1966;45:493-6

17. Anvikar AR, Deshmukh AB, Karyakarte RP, Damle AS, Patwardhan NS, Malik AK, et al. A one year prospective study of 3280 surgical wounds. Indian J Medical Microbiol. 1999;17(3):129-32.

18. Lilani SP, Jangale N, Chowdhary A, Daver GB. Surgical site infection in clean and clean-contaminated cases. Indian $\mathrm{J}$ Medical Microbiol. 2005;23(4):249-52.

19. Khan MA, Ansari MN, Bano S. Post operative wound Infection. Ind. J. Surg. 1985;48:383-86.

20. Rao AS, Harsha M. Postoperative wound infections. J. Indian M.A. 1975;64(4):90-3.
21. Tripathy BS, Roy N. Post-operative wound sepsis. Ind. J. Surg. 1984;47:285-8.

22. Kamath N, Swaminathan R, Sonawane J, Bharos N. Bacteriological profile of surgical site infections in a tertiary care center in Navi Mumbai [abstract]. Proceedings of the 16th Maharashtra Chapter Conference of IAMM; 2010 Sept 24-26; Karad, Maharashtra. p. 61.

23. Berard F, Gandon J. Factors influencing the Incidence of wound infection. Ann Surg. 1964;160:32-81.

24. Cruse P JE. Surgical infection: Incisional wounds. In Bennet JV, Brachman PS (eds), Hospital Infections (ed2). Boston, Toronto Little Brown and Company 1986; 423.

25. Wong ES. Surgical site infections. In: Mayhall CG, editor. Hospital epidemiology and infection control. 1st ed. USA: Williams and Wilkins; 1996. pp. 154-74.

26. Cruse P JE, Foord R.A five year prospective study of 23, 649. surgical wounds. Arch surg 1973; 107; 206.

27. Garibaldi RA, cushing D, Lorer T. Risk factors for Post operative infection. Am J Med 1991 ; 91 (Suppl 3B) : 1585.

28. Eriksen NH, Espersen F, Rosdahl VT, Jensen K. Carriage of Staphylococcus aureus among 104 healthy persons during a 19-month period. Epidemiol Infect 1995; 115(1): 51-60.

29. Whyte W, Hambraeus A, Laurell G, Hoborn J. The relative importance of routes and sources of wound contamination during general Surgery. I. Non-airborne. $J$ Hosp Infect 1991; 18(2): 93-107.

30. Byrne DJ, Phillips G, Napier A, Cuschieri A. The effect of whole body disinfection on intraoperative wound contamination. J Hosp Infect 1991; 18(2): 145-8.

31. Cruse PJ, Foord R. The epidemiology of wound infection. A 10-year prospective study of 62,939 wounds. Surg Clin North Am 1980; 60(1): 27-40.

32. Leaper D J, Gottrup F. Surgical wounds. In: Leaper DJ, Harding KG, editors. Wounds: biology and management. Oxford: Oxford University Press, 1998; 23-40. 